\title{
Impurities/Degradation Products/Related Substances Assessment
}

National Cancer Institute

\section{Source}

National Cancer Institute. Impurities/Degradation Products/Related Substances

Assessment. NCl Thesaurus. Code C134254.

Analytical procedures that determine the presence of a component of the material that is not the chemical entity defined as the material. 